\title{
The management of hyponatremia in HIV disease
}

\author{
Madhav C. Menon • Amarinder S. Garcha • \\ Apurv Khanna
}

Received: 28 October 2013/Accepted: 29 October 2013/Published online: 7 December 2013

(C) Italian Society of Nephrology 2013

\section{Dear Editor,}

We thank Musso and colleagues for their interest in our work [1]. They report evidence of a hitherto unreported signal for potential tubular dysfunction and impaired water handling in patients with HIV disease that is independent of anti-retroviral therapy and glomerular filtration rate [2]. Extensive mechanistic studies have suggested direct invasion of tubular epithelial cells by HIV virus with both in vitro and in vivo evidence of direct pathogenicity(see review) [3]. Notably, this invasion has been reported in the absence of detectable viremia [4]. Their study, in our opinion, may mark the first physiological documentation of these effects.

We would, however, like to raise the following caveat. The use of creatinine-based estimations may be significantly affected by creatinine generation (i.e., muscle mass), specifically in the HIV population [5]. The measurement of renal function (i.e. GFR) in these patients should be validated using a more specific non-creatinine assay to truly ascribe this impaired handling to a tubular effect that is independent of GFR.

\section{References}

1. Menon M, Garcha A, Khanna A (2013) The management of hyponatremia in HIV disease. J Nephrol 26(01):61-72

2. Musso C, Bellizzi V, Belloso W (2013) Altered water renal handling in patients with HIV infection. J Nephrol. doi:10.1007/ s40620-013-0004-5

3. Leventhal JS, Ross MJ (2008) Pathogenesis of HIV-associated nephropathy. Semin Nephrol 28:523-534

4. Winston JA, Bruggeman LA, Ross MD et al (2001) Nephropathy and establishment of a renal reservoir of HIV type 1 during primary infection. N Engl J Med 344:1979-1984

5. Wyatt CM, Schwartz GJ, Owino Ong'or W et al (2013) Estimating kidney function in HIV-infected adults in Kenya: comparison to a direct measure of glomerular filtration rate by iohexol clearance. PLoS ONE 8:e69601

\section{C. Menon}

Division of Nephrology, Mount Sinai School of Medicine,

New York, NY, USA

e-mail: madhav.menon@mssm.edu

\author{
A. S. Garcha \\ Renal Electrolyte and Hypertension Division, Perelman School \\ of Medicine at the University of Pennsylvania, Philadelphia, PA, \\ USA \\ e-mail: amarinder.garcha@uphs.upenn.edu
}

A. Khanna $(\bowtie)$

Division of Nephrology, SUNY Upstate Medical University,

Syracuse, NY 13210, USA

e-mail: khannaa@upstate.edu 